\title{
Relevance of Circulating Nucleosomes, HMGB1 and SRAGE for Prostate Cancer Diagnosis
}

\author{
MANUEL M. GARRIDO ${ }^{1,2}$, RUY M. RIBEIRO ${ }^{3}$, KIMBERLY KRÜGER $^{4}$, \\ LUÍS C. PINHEIRO ${ }^{5,6}$, JOÃO T. GUIMARÃES ${ }^{7,8,9}$ and STEFAN HOLDENRIEDER ${ }^{4}$
}

\author{
${ }^{1}$ Department of Clinical Pathology, Centro Hospitalar Universitário de Lisboa Central, Lisbon, Portugal; \\ ${ }^{2}$ Department of Laboratory Medicine, Faculdade de Medicina da Universidade de Lisboa, Lisbon, Portugal; \\ ${ }^{3}$ Biomathematics Laboratory, Faculdade de Medicina da Universidade de Lisboa, Lisbon, Portugal; \\ ${ }^{4}$ Institute of Laboratory Medicine, Munich Biomarker Research Center, \\ Deutsches Herzzentrum München, Technische Universität München, Munich, Germany; \\ ${ }^{5}$ Department of Urology, Centro Hospitalar Universitário de Lisboa Central, Lisbon, Portugal; \\ ${ }^{6}$ Department of Urology, Faculdade de Ciências Médicas da Universidade Nova de Lisboa, Lisbon, Portugal; \\ ${ }^{7}$ Department of Clinical Pathology, Centro Hospitalar Universitário de São João, Porto, Portugal; \\ ${ }^{8}$ Department of Biomedicine, Faculdade de Medicina, Universidade do Porto, Porto, Portugal; \\ ${ }^{9}$ EPIUnit, Instituto de Saúde Pública, Universidade do Porto, Porto, Portugal
}

\begin{abstract}
Background/Aim: Evasion from cell death occurs in prostate cancer $(\mathrm{PCa})$. We verified whether serum levels of cell death markers can have diagnostic value in PCa. Patients and Methods: A total of 233 men scheduled for prostate biopsy [prostate specific antigen (PSA) level: 2-10 $\mathrm{ng} / \mathrm{mll}$ were enrolled. Serum nucleosomes, nucleosomes containing the H3 histone (H3), high mobility group box 1 (HMGB1), and soluble receptor for advanced glycation end products (sRAGE) were analyzed by enzyme immunoassays. Results: There were no differences ( $p>0.05)$ in nucleosomes, $H 3$, and sRAGE levels between patients with and without $P C a$ or clinically significant PCa (csPCa). HMGB1 had lower levels in $P C$ a patients $(p=0.023)$ and was a predictor of PCa ( $p=0.047)$, but not of csPCa $(p=0.180)$. Conclusion: In patients with critical PSA levels between 2-10 $\mathrm{ng} / \mathrm{ml}$, $H M G B 1$ had some diagnostic value for overall $P C a$ detection, but it was not predictive of csPCa. Nucleosomes, $H 3$ and sRAGE did not discriminate between PCa or csPCa and controls.
\end{abstract}

This article is freely accessible online.

Correspondence to: Manuel M. Garrido, MD, Centro Hospitalar Universitário de Lisboa Central, Hospital de São José, Serviço de Patologia Clínica, Rua José António Serrano, 1150-199 Lisbon, Portugal. Tel: +35 1218841879, e-mail: manuel.agarrido@chlc.minsaude.pt

Key Words: Prostate cancer, circulating nucleosomes, cell death detection ELISA, immunogenic cell death markers, sRAGE, HMGB1.
Resistance to cell death is a mechanism that has been described in tumorigenesis (1). This evasion from apoptosis is a consequence of genetic lesions that lead to the activation of pro-survival genes and/or the disabling of pro-apoptotic genes. This allows not only neoplastic transformation but also the continued growth of tumor cells (2). Several anticancer therapies, such as immunotherapy, elicit programmed cell death in cancer cells to counteract evasion from apoptosis (3).

In prostate cancer (PCa), evasion from cell death has been shown to play an important role in disease progression towards hormone independence and treatment resistance (4). In the normal prostate, there is a continuous turnover of epithelial cells, which relies on a balance between cell proliferation and cell death. However, in $\mathrm{PCa}$, this balance is lost, leading to continuous cell proliferation, which is largely androgen-driven. Androgen withdrawal induces apoptosis in androgen-dependent PCa cells. In contrast, androgen-independent $\mathrm{PCa}$ cells do not undergo programmed cell death, even upon androgen ablation. However, even these androgen-independent PCa cells maintain the ability to undergo programmed cell death. Therefore, several therapies aim to induce androgen-independent cells to initiate apoptosis (5). However, since some defects in programmed cell death pathways can prevent the success of these cancer therapies, more insight into the mechanisms of apoptosis in $\mathrm{PCa}$ is required to develop more effective therapeutic approaches (3). In PCa, there have been reports of several alterations that can promote the inhibition of programmed cell death, namely the over-expression of anti-apoptotic proteins, such as Bcl-2 and BclXL, as well as the activation 
of pro-survival proteins (Akt and NF-kB) (6). The loss of tumor suppressors (e.g., p53, PTEN, and Bin1) also contributes to cell death resistance in $\mathrm{PCa}$. The accumulation of these molecular mechanisms, along with others that accumulate during cancer progression, contribute to tumor aggressiveness and the development of androgenindependent metastasis (6).

Cell death leads to the release of some biomarkers into the circulation. This is the case for nucleosomes, whose circulating levels may rise due to the apoptosis that occurs in highly proliferating tumors, whether spontaneously or as a result of anticancer therapy (7). Nucleosomes are basic elements of chromatin, composed of an octamer of histones (H2A, H2B, H3, and H4) and 146 base pairs of DNA. Between them, there is a chain-like structure composed of DNA that is stabilized by histone H1. This linking chain is the preferential site for the binding of endonucleases, which are activated during apoptosis. Endonucleases cleave chromatin into oligo- and mononucleosomes. As a consequence, nucleosomes are released in higher amounts in the blood of patients with health conditions that imply an increased cell death rate, as is the case for cancer, acute inflammation, or autoimmune diseases (8). Circulating nucleosomes can be quantified using immunoassays $(7,8)$.

Further biomarkers that are released into the blood circulation during apoptosis are high molecular group box 1 (HMGB1) as well as the soluble receptor for advanced glycation products (sRAGE), which binds to HMGB1 and inhibits its effects (9). Since these biomarkers are involved in immune stimulation after cell death, they are considered as immunogenic cell death (ICD) markers (10). HMGB1 is a protein present in all human cells, where it binds to DNA and has functions related to DNA transcription, recombination, and repair. However, it also works in the extracellular space, where it interacts with the immune system. HMGB1 has also been reported to participate in the apoptosis evasion mechanism in cancer (9). An overexpression of HMGB1 has been shown to occur in PCa cells, mostly in hormone-resistant metastatic PCa (11).

RAGE is a member of the immunoglobulin superfamily and a transmembrane protein. Its extracellular domain can be detected in the extracellular space and blood circulation, and is known as soluble RAGE (sRAGE). Higher levels of RAGE expression are found whenever inflammatory mediators or ligands, such as HMGB1, are more expressed, which happens in cancer (9). Besides binding to extracellular HMGB1, sRAGE also binds to S100-family proteins, immunoglobulin light chains, and nucleic acids. It participates in signaling pathways involved in inflammation, cancer, and autoimmune diseases. When released into the blood circulation, sRAGE probably acts as a decoy receptor for HMGB1, preventing its proimmunogenic effects (9).
Increased RAGE mRNA expression has been described in hormone-refractory PCa tissue (12).

PCa has a very high incidence in men worldwide (13). However, a significant proportion of all diagnosed cancers are clinically insignificant and would probably remain silent during an individual's lifetime. This overdiagnosis, which also leads to overtreatment, is largely due to the lack of specificity of the prostate-specific antigen (PSA) for $\mathrm{PCa}$, as well as its inability to discriminate the most aggressive forms of PCa $(14,15)$. This issues assume greater relevance in the PSA range between 2 and $10 \mathrm{ng} / \mathrm{ml}$, where decisions concerning prostate biopsies become more challenging (16). Therefore, there is a need to find new biomarkers that, together with PSA, may help to identify clinically significant PCa (csPCa) (14).

Given the aforementioned importance of cell death processes in cancer, and since several biomarkers related to cell death can be found in blood, we aimed to verify whether serum levels of cell death-related nucleosomes and ICD markers HMGB1 and sRAGE, can be related to PCa and have diagnostic value, within the $2-10 \mathrm{ng} / \mathrm{ml} \mathrm{PSA}$ range, considering both overall $\mathrm{PCa}$ and csPCa as outcomes.

\section{Patients and Methods}

Study design. This is an observational study in which we enrolled 233 patients with a first or repeated prostate biopsy scheduled due to PCa suspicion. All biopsies had at least 12 cores and were examined by the same pathologist. Biopsy results were given according to the updated definitions of the International Society of Urological Pathology (17). All patients had a total PSA level between 2 and $10 \mathrm{ng} / \mathrm{ml}$.

Written informed consent was obtained from all patients who participated in the study, which was approved by the Institutional Review Board and complied with the Helsinki declaration.

Blood draw for biomarkers assessment was performed on the same day as the prostate biopsy, but prior to it. Serum samples were used to quantify circulating nucleosomes and the ICD markers HMGB1 and sRAGE. The values of the biomarkers were compared between groups of patients, taking both overall $\mathrm{PCa}$ and csPCa as outcomes. We defined csPCa according to the criteria established by the Prostate Cancer Research International Active Surveillance (PRIAS) study for patients with serum PSA levels $\leq 10 \mathrm{ng} / \mathrm{ml}$ (18). Therefore, patients with at least one of the following characteristics were classified as having csPCa: regional lymph node metastasis (N1), distant metastasis (M1), extracapsular disease (T $\geq 3$ ), PSA density $\geq 0.2 \mathrm{ng} / \mathrm{ml}$ per milliliter, total Gleason score $(\mathrm{GS}) \geq 7$, number of positive biopsy cores $>2$ or, whenever saturation biopsies were made ( $\geq 20$ cores), $>15 \%$ of positive cores (or more than 4 positive cores, if $15 \%$ of positive cores exceeded this number) (19).

Study subjects. A total of 233 patients from the Urology Department of the Central Lisbon University Hospital Center were enrolled in the study. The inclusion criteria were: PSA between 2 and $10 \mathrm{ng} / \mathrm{ml}$, no previous history of $\mathrm{PCa}$, no previous transurethral resection of the prostate, no therapy with 5 - $\alpha$-reductase inhibitors or androgens, no urinary infection contemporary to blood collection, or acute bacterial 
Table I. Age and biomarkers' values distribution between the different groups of patients.

\begin{tabular}{|c|c|c|c|c|c|c|}
\hline & $\begin{array}{c}\mathrm{PCa} \\
\mathrm{n}=118\end{array}$ & $\begin{array}{l}\text { Without PCa } \\
n=115\end{array}$ & $p$-Value & $\begin{array}{l}\mathrm{csPCa} \\
\mathrm{n}=100\end{array}$ & $\begin{array}{c}\text { Without csPCa } \\
n=133\end{array}$ & $p$-Value \\
\hline $\begin{array}{l}\text { Age, years, median } \\
\text { (IQR) }\end{array}$ & $\begin{array}{c}69.0 \\
(62.8-73.0)\end{array}$ & $\begin{array}{c}65.0 \\
(60.0-71.0)\end{array}$ & $0.012^{\mathrm{a}}$ & $\begin{array}{c}69.0 \\
(63.0-73.0)\end{array}$ & $\begin{array}{c}66.0 \\
(61.0-71.0)\end{array}$ & $0.036^{\mathrm{a}}$ \\
\hline $\mathrm{PSA}, \mathrm{ng} / \mathrm{ml}$, mean $\pm \mathrm{SD}$ & $6.6 \pm 2.0$ & $6.0 \pm 2.0$ & $0.014^{\mathrm{b}}$ & $6.8 \pm 1.9$ & $5.9 \pm 2.0$ & $<0.001^{\mathrm{b}}$ \\
\hline $\begin{array}{l}\mathrm{CDDE}^{*}, \mathrm{aU}, \text { median } \\
\text { (IQR) } \\
\text { [undetectable: } \mathrm{n}=8 \text { ] }\end{array}$ & $\begin{array}{c}59.0 \\
(27.8-111.0)\end{array}$ & $\begin{array}{c}53.4 \\
(30.8-111.2)\end{array}$ & $0.432^{\mathrm{a}}$ & $\begin{array}{c}60.8 \\
(29.4-112.0)\end{array}$ & $\begin{array}{c}53.3 \\
(28.2-110.1)\end{array}$ & $0.201^{\mathrm{a}}$ \\
\hline $\begin{array}{l}\mathrm{H} 3^{* *}, \mu \mathrm{g} / \mathrm{ml}, \text { median } \\
\text { (IQR) } \\
\text { [>upper detection limit: } \mathrm{n}=2]\end{array}$ & $\begin{array}{c}0.9 \\
(0.6-1.1)\end{array}$ & $\begin{array}{c}0.8 \\
(0.5-1.2)\end{array}$ & $0.845^{\mathrm{a}}$ & $\begin{array}{c}0.9 \\
(0.6-1.1)\end{array}$ & $\begin{array}{c}0.8 \\
(0.5-1.2)\end{array}$ & $0.593^{a}$ \\
\hline $\begin{array}{l}\text { HMGB } 1 *, n g / m l, \text { median } \\
\text { (IQR) } \\
\text { [undetectable: } n=40]\end{array}$ & $\begin{array}{c}1.5 \\
(0.8-2.6)\end{array}$ & $\begin{array}{c}2.0 \\
(1.0-3.6)\end{array}$ & $0.023^{\mathrm{a}}$ & $\begin{array}{c}1.5 \\
(0.9-2.7)\end{array}$ & $\begin{array}{c}1.9 \\
(1.0-3.3)\end{array}$ & $0.198^{\mathrm{a}}$ \\
\hline $\begin{array}{l}\text { sRAGE, pg/ml, median } \\
\text { (IQR) }\end{array}$ & $\begin{array}{c}973.2 \\
(723.1-1,330.8)\end{array}$ & $\begin{array}{c}987.7 \\
(756.1-1,349.4)\end{array}$ & $0.903^{\mathrm{a}}$ & $\begin{array}{c}1,015.8 \\
(733.9-1,423.6)\end{array}$ & $\begin{array}{c}957.6 \\
(750.0-1,274.4)\end{array}$ & $0.462^{\mathrm{a}}$ \\
\hline
\end{tabular}

PCa: Prostate cancer; csPCa: clinically significant prostate cancer; IQR: interquartile range; PSA: prostate-specific antigen; SD: standard deviation; CDDE: Cell Death Detection Enzyme-Linked Immunosorbent Assay; aU: absorbance units; H3: nucleosomes containing the H3 histone; HMGB1: high mobility group box 1; sRAGE: soluble receptor for advanced glycation end products. aMann-Whitney test; bStudent's $t$-test. *Undetectable results were entered as equal to the analytical sensitivity. **Results above the upper detection limit were entered as equal to the method's linearity.

prostatitis in the three months prior to the biopsy. Patients with heavy hemolyzed serum samples were excluded. Between December 2017 and October 2019, all consecutive patients from the Urology Department, who had a prostate biopsy scheduled and who met the inclusion criteria and provided written informed consent, were enrolled in this study.

Blood samples processing and laboratory assays. Blood samples were centrifuged and kept at $2-8^{\circ} \mathrm{C}$ within three hours after blood collection. Serum was separated into secondary tubes that were frozen at $-80^{\circ} \mathrm{C}$, no longer than $8 \mathrm{~h}$ after blood collection. The serum samples were transported on dry ice to the Munich Biomarker Research Center, Institute of Laboratory Medicine of the German Heart Centre Munich, Clinics at the Technical University Munich, and kept at $-80^{\circ} \mathrm{C}$ until the assays were performed.

Serum samples were thawed shortly before the biomarkers assays performance. All biomarkers were analyzed using enzyme-linked immunosorbent assays (ELISA), which were performed manually and on a DS2 ${ }^{\circledR}$ ELISA analyzer (Dynex Technologies Corp., Chantilly, VA, USA).

Two different assays were used to quantify circulating nucleosomes: the Cell Death Detection ELISA (CDDE; Roche Diagnostics, GmbH, Mannheim, Germany) and the Nu.Q ${ }^{\mathrm{TM}} \mathrm{H} 3$ Assay (Volition SRL, Isnes, Belgium). The CDDE assay detects mono and oligonucleosomes containing histones H1, H2A, H2B, H3 and $\mathrm{H} 4$, while the Nu. $\mathrm{Q}^{\mathrm{TM}} \mathrm{H} 3$ assay quantifies total circulating nucleosomes containing the $\mathrm{H} 3$ histone.

Serum HMGB1 was quantified using the IBL HMGB1 ELISA kit (IBL International, GmbH, Hamburg, Germany) and sRAGE was performed using the Human RAGE Quantikine ${ }^{\circledR}$ ELISA kit (R\&D Systems, Inc., McKinley Place, MN, USA). Beckman Coulter Hybritech ${ }^{\circledR}$ PSA was performed using the Access 2 immunoassay system (Beckman Coulter, Brea, CA, USA).

Statistical analysis. Continuous variables with a normal distribution were described as mean \pm standard deviation $(\mathrm{SD})$, while the median and interquartile range (IQR) were used to characterize the nonnormally distributed continuous variables. Parametric and nonparametric tests were used to compare the values between groups. Univariate and multivariate logistic regression analyses were performed. Statistical significance was set at $p<0.05$. Statistical analysis was performed using IBM $^{\circledR}$ SPSS $^{\circledR}$ Statistics 26.0 (IBM Corp., Armonk, NY, USA, 2019).

\section{Results}

Of the 233 men who entered the study, 118 (50.6\%) had PCa, while 115 (49.4\%) had no cancer. csPCa was detected in 100 patients (42.9\%). The remaining 133 (57.1\%) men had no cancer or clinically insignificant disease. The 233 participants had a median age of 67.0 years (IQR=61.072.5 ), with a minimum of 42 years and a maximum of 87 years. The age distribution between the different groups of patients, as well as the values of all the measured biomarkers, are shown in Table I.

Both CDDE and total $\mathrm{H} 3$ nucleosomes concentrations did not show significant differences between men with and without $\mathrm{PCa}$, or with and without csPCa $(p>0.05)$. Concerning the ICD markers, sRAGE values were not significantly different between patients with $\mathrm{PCa}$ or with csPCa and patients without cancer or with clinically insignificant disease $(p>0.05)$. HMGB1 serum concentrations were significantly higher in patients without PCa than in those with cancer $(p=0.023$; Figure 1). However, there were no significant differences in HMGB1 values when comparing patients with csPCa with all the others $(p=0.198)$. HMGB1 was undetectable in the serum of 40 patients: 16 without cancer and 24 with PCa. 


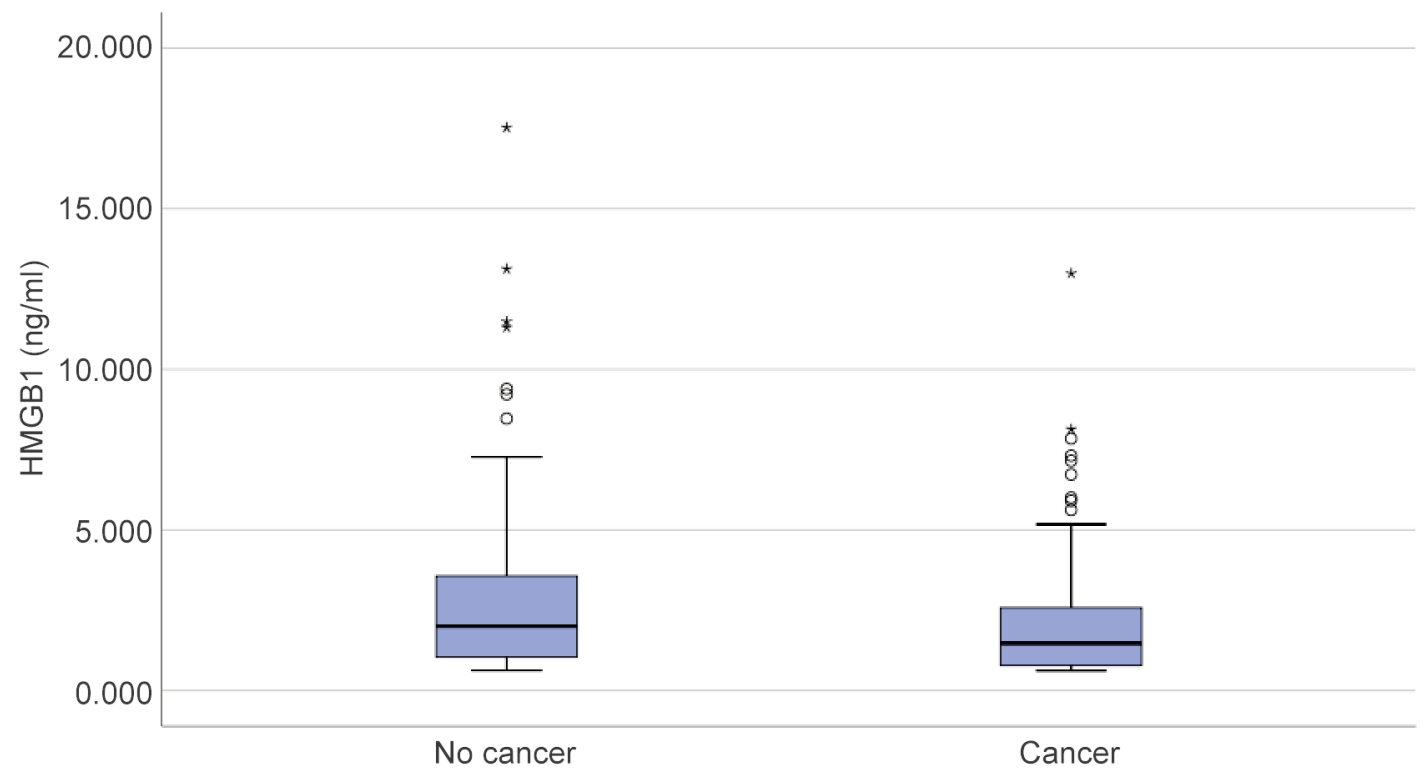

Figure 1. Distribution of high mobility group box 1 (HMGB1) values between patients without and with prostate cancer.

Table II. Univariate logistic regression analysis for the prediction of overall and of clinically significant prostate cancer.

\begin{tabular}{lccllr}
\hline & \multicolumn{2}{c}{ Overall PCa } & & \multicolumn{2}{c}{ Clinically significant PCa } \\
\cline { 2 - 3 } Biomarker & OR (95\%CI) & $p$-Value & & OR $(95 \% \mathrm{CI})$ & $p$-Value \\
\hline PSA & $1.18(1.03-1.35)$ & 0.015 & & $1.29(1.13-1.49)$ & $<0.001$ \\
HMGB1 & $0.89(0.79-1.00)$ & 0.047 & & $0.92(0.82-1.04)$ & 0.180 \\
\hline
\end{tabular}

PCa: Prostate cancer; PSA: prostate-specific antigen; HMGB1: high mobility group box 1; CI: confidence interval; OR: odds ratio.

On univariate logistic regression analysis (Table II), HMGB1 was a predictor of overall PCa $(p=0.047)$, as well as PSA $(p=0.015)$. However, only PSA was predictive of $\operatorname{csPCa}(p<0.001)$, and HMGB1 was not $(p=0.180)$.

Multivariate logistic regression analysis (Table III) revealed that HMGB1 was an independent predictor of overall PCa $(p=0.040)$ when added to PSA.

\section{Discussion}

Among the four laboratory serum tests evaluated in this study, only the HMGB1 serum assay showed significant differences between men with and without PCa. Patients without PCa had significantly higher levels of this protein than those with PCa. Concerning csPCa, the levels of HMGB1 were also higher in men with insignificant PCa or without cancer, although the difference was not statistically
Table III. Multivariate logistic regression analysis for the prediction of overall and of clinically significant prostate cancer.

\begin{tabular}{lccccr}
\hline & \multicolumn{2}{c}{ Overall PCa } & & \multicolumn{2}{c}{ Clinically significant PCa } \\
\cline { 2 - 3 } \cline { 6 - 6 } Biomarker & OR $(95 \% \mathrm{CI})$ & $p$-Value & & OR (95\%CI) & $p$-Value \\
\hline PSA & $1.19(1.04-1.36)$ & 0.013 & & $1.30(1.13-1.50)$ & $<0.001$ \\
HMGB1 & $0.89(0.79-1.00)$ & 0.040 & & $0.92(0.82-1.03)$ & 0.144 \\
\hline
\end{tabular}

PCa: Prostate cancer; PSA: prostate-specific antigen; HMGB1: high mobility group box 1; CI: confidence interval; OR: odds ratio.

significant. Although only a few studies have been published on HMGB1 in $\mathrm{PCa}$, there seems to be a contradiction between our findings and those of other authors. Zhao et al. reported that tissue expression of HMGB 1 was positive in $68.2 \%$ of PCa cases $(\mathrm{n}=85)$ versus $33.3 \%$ of patients with benign prostatic hyperplasia (BPH) $(n=30)$. Moreover, the expression of HMGB1 was significantly higher in $\mathrm{PCa}$ patients than in $\mathrm{BPH}$ patients (20). In addition, Ishiguro et al. found a significantly higher expression of HMGB1 mRNA in untreated primary $\mathrm{PCa}$ tissue than in normal prostate tissue (12). However, these studies did not evaluate the serum levels of HMGB1, but instead, its tissue expression. Therefore, we hypothesize that there is no direct correlation between the tissue expression of this protein and the serum levels. One possible explanation for this is that the release of this protein into the extracellular space occurs mostly during 
apoptosis or after therapy-induced tumor necrosis. In this study, we used untreated patients who had just been submitted to diagnostic procedures. Therefore, we could not determine the effects of therapeutic-induced tumor necrosis. On the other hand, there is evasion from apoptosis in cancer, which could explain the lower level of apoptosis in the group of patients with PCa and with a PSA level between 2 and $10 \mathrm{ng} / \mathrm{ml}$. Hence, there could be a lower level of HMGB1 release into the extracellular space and, as a consequence, a lower level of this protein in the serum of patients with $\mathrm{PCa}$.

Interestingly, in addition to the significantly lower serum levels of HMGB1 in men with PCa, we found that this protein is a predictor of $\mathrm{PCa}$ on univariate analysis. Moreover, it maintains and independent predictor status when added to PSA, concerning $\mathrm{PCa}$ detection, in multivariate logistic regression analysis. Although HMGB 1 is unable to predict clinically significant forms of $\mathrm{PCa}$, it is noteworthy that it can add value to PSA in this group of patients, with a PSA level between 2 and $10 \mathrm{ng} / \mathrm{ml}$. Furthermore, the levels of sRAGE were not different between patients with or without PCa.

Concerning the results of the assays quantifying the serum levels of circulating nucleosomes - CDDE and total nucleosomes containing the $\mathrm{H} 3$ histone - there were no significant differences between patients with or without $\mathrm{PCa}$, and also no significant differences were found when considering csPCa as the outcome. The serum quantification of nucleosomes has some issues, as they are quickly removed from the circulation by the liver or through immunological pathways (21). Moreover, endonucleases are present in samples that affect the in vitro stability of nucleosomes (8). Therefore, we only found very low concentrations of serum nucleosomes.

Our findings relating to circulating nucleosomes are consistent with those reported by other authors. Several studies have shown higher levels of circulating nucleosomes in different cancers, including PCa. However, in those studies, the differences were also not statistically significant when compared with patients without cancer $(22,23)$.

This study has some limitations, as other clinical conditions that could affect the serum levels of cell death markers were not documented. This could be the case of acute inflammation, autoimmune diseases, infections, and ischemic conditions $(8,24,25)$. Actually, the several outliers that can be seen in Figure 1 could potentially be a reflection of some of those situations.

In summary, our results indicate that HMGB 1 could, together with PSA, have a role as an adjunctive biomarker in the diagnosis of $\mathrm{PCa}$, although it has no predictive value in the detection of csPCa, in patients within the PSA range of 2 to $10 \mathrm{ng} / \mathrm{ml}$. sRAGE and circulating nucleosomes have no diagnostic value for PCa.

\section{Funding}

The Authors received no financial support for the research, authorship, and/or publication of this article.

\section{Conflicts of Interest}

The Authors declare no conflicts of interest related to this study.

\section{Authors' Contributions}

The Authors confirm their contribution to the paper as follows: study conception and design: Manuel M. Garrido and Stefan Holdenrieder; data collection: Manuel M. Garrido and Kimberly Krüger; analysis and interpretation of results: Manuel M. Garrido and Ruy M. Ribeiro; draft manuscript preparation: Manuel M. Garrido; critical review of the manuscript: Stefan Holdenrieder, Ruy M. Ribeiro, Kimberly Krüger, João T. Guimarães and Luís C. Pinheiro. All Authors approved the final version of the manuscript.

\section{References}

1 Labi V and Erlacher M: How cell death shapes cancer. Cell Death Dis 6: e1675, 2015. PMID: 25741600. DOI: 10.1038/cddis.2015.20

2 Kelly GL and Strasser A: The essential role of evasion from cell death in cancer. Adv Cancer Res 111: 39-96, 2011. PMID: 21704830. DOI: 10.1016/B978-0-12-385524-4.00002-7

3 Fulda S: Regulation of cell death in cancer-possible implications for immunotherapy. Front Oncol 3: 29, 2013. PMID: 23441073. DOI: $10.3389 /$ fonc 2013.00029

4 McKenzie S and Kyprianou N: Apoptosis evasion: the role of survival pathways in prostate cancer progression and therapeutic resistance. J Cell Biochem 97(1): 18-32, 2006. PMID: 16216007. DOI: $10.1002 /$ jcb. 20634

5 Denmeade SR, Lin XS and Isaacs JT: Role of programmed (apoptotic) cell death during the progression and therapy for prostate cancer. Prostate 28(4): 251-265, 1996. PMID: 8602401. DOI: $10.1002 /($ SICI) 1097-0045(199604)28:4<251::AID-PROS $6>3.0 . \mathrm{CO} ; 2-\mathrm{G}$

6 Gurumurthy S, Vasudevan KM and Rangnekar VM: Regulation of apoptosis in prostate cancer. Cancer Metastasis Rev 20(3-4): 225-243, 2001. PMID: 12085964. DOI: 10.1023/a:101558 3310759

7 Holdenrieder S, Stieber P, Förg T, Kühl M, Schulz L, Busch M, Schalhorn A and Seidel D: Apoptosis in serum of patients with solid tumours. Anticancer Res 19(4A): 2721-2724, 1999. PMID: 10470228.

8 Holdenrieder S, Stieber P, Bodenmüller H, Fertig G, Fürst H, Schmeller N, Untch M and Seidel D: Nucleosomes in serum as a marker for cell death. Clin Chem Lab Med 39(7): 596-605, 2001. PMID: 11522104. DOI: 10.1515/CCLM.2001.095

9 Pilzweger $\mathrm{C}$ and Holdenrieder S: Circulating HMGB1 and RAGE as clinical biomarkers in malignant and autoimmune diseases. Diagnostics (Basel) 5(2): 219-253, 2015. PMID: 26854151. DOI: 10.3390/diagnostics5020219

10 Fahmueller YN, Nagel D, Hoffmann RT, Tatsch K, Jakobs T, Stieber $\mathrm{P}$ and Holdenrieder $\mathrm{S}$ : Immunogenic cell death biomarkers HMGB1, RAGE, and DNAse indicate response to 
radioembolization therapy and prognosis in colorectal cancer patients. Int J Cancer 132(10): 2349-2358, 2013. PMID: 23047645. DOI: $10.1002 /$ ijc. 27894

11 Gnanasekar M, Kalyanasundaram R, Zheng G, Chen A, Bosland MC and Kajdacsy-Balla A: HMGB 1: A promising therapeutic target for prostate cancer. Prostate Cancer 2013: 157103, 2013. PMID: 23766911. DOI: 10.1155/2013/157103

12 Ishiguro H, Nakaigawa N, Miyoshi Y, Fujinami K, Kubota Y and Uemura H: Receptor for advanced glycation end products (RAGE) and its ligand, amphoterin are overexpressed and associated with prostate cancer development. Prostate 64(1): 92100, 2005. PMID: 15666359. DOI: 10.1002/pros.20219

13 Sung H, Ferlay J, Siegel RL, Laversanne M, Soerjomataram I, Jemal A and Bray F: Global Cancer Statistics 2020: GLOBOCAN estimates of incidence and mortality worldwide for 36 cancers in 185 countries. CA Cancer J Clin 71(3): 209249, 2021. PMID: 33538338. DOI: 10.3322/caac.21660

14 Ziglioli F, Granelli G, Cavalieri D, Bocchialini T and Maestroni U: What chance do we have to decrease prostate cancer overdiagnosis and overtreatment? A narrative review. Acta Biomed 90(4): 423-426, 2019. PMID: 31910165. DOI: 10.23750/abm.v90i4.9070

15 Loeb S, Bjurlin MA, Nicholson J, Tammela TL, Penson DF, Carter HB, Carroll $\mathrm{P}$ and Etzioni R: Overdiagnosis and overtreatment of prostate cancer. Eur Urol 65(6): 1046-1055, 2014. PMID: 24439788. DOI: 10.1016/j.eururo.2013.12.062

16 Ross T, Ahmed K, Raison N, Challacombe B and Dasgupta P: Clarifying the PSA grey zone: The management of patients with a borderline PSA. Int J Clin Pract 70(11): 950-959, 2016. PMID: 27672001. DOI: $10.1111 /$ ijcp.12883

17 Epstein JI, Egevad L, Amin MB, Delahunt B, Srigley JR, Humphrey PA and Grading Committee: The 2014 International Society of Urological Pathology (ISUP) consensus conference on Gleason grading of prostatic carcinoma: Definition of grading patterns and proposal for a new grading system. Am J Surg Pathol 40(2): 244-252, 2016. PMID: 26492179. DOI: 10.1097/ PAS.0000000000000530

18 Bul M, Zhu X, Valdagni R, Pickles T, Kakehi Y, Rannikko A, Bjartell A, van der Schoot DK, Cornel EB, Conti GN, Boevé ER, Staerman F, Vis-Maters JJ, Vergunst H, Jaspars JJ, Strölin $\mathrm{P}$, van Muilekom E, Schröder FH, Bangma CH and Roobol MJ: Active surveillance for low-risk prostate cancer worldwide: the PRIAS study. Eur Urol 63(4): 597-603, 2013. PMID: 23159452. DOI: $10.1016 /$ j.eururo.2012.11.005
19 Bokhorst LP, Valdagni R, Rannikko A, Kakehi Y, Pickles T, Bangma CH, Roobol MJ and PRIAS study group: A decade of active surveillance in the PRIAS study: An update and evaluation of the criteria used to recommend a switch to active treatment. Eur Urol 70(6): 954-960, 2016. PMID: 27329565. DOI: 10.1016/j.eururo.2016.06.007

20 Zhao CB, Bao JM, Lu YJ, Zhao T, Zhou XH, Zheng DY and Zhao SC: Co-expression of RAGE and HMGB1 is associated with cancer progression and poor patient outcome of prostate cancer. Am J Cancer Res 4(4): 369-377, 2014. PMID: 25057439.

21 Gauthier VJ, Tyler LN and Mannik M: Blood clearance kinetics and liver uptake of mononucleosomes in mice. J Immunol 156(3): 1151-1156, 1996. PMID: 8557992.

22 McAnena P, Brown JA and Kerin MJ: Circulating nucleosomes and nucleosome modifications as biomarkers in cancer. Cancers (Basel) 9(1): 5, 2017. PMID: 28075351. DOI: 10.3390/ cancers 9010005

23 Holdenrieder S, Stieber P, Bodenmüller H, Busch M, Fertig G, Fürst H, Schalhorn A, Schmeller N, Untch M and Seidel D: Nucleosomes in serum of patients with benign and malignant diseases. Int J Cancer 95(2): 114-120, 2001. PMID: 11241322. DOI: 10.1002/1097-0215(20010320)95:2<114::aid-ijc1020>3.0. co;2-q

24 Fukami A, Adachi H, Yamagishi S, Matsui T, Ueda S, Nakamura K, Enomoto M, Otsuka M, Kumagae S, Nanjo Y, Kumagai E, Esaki E, Murayama K, Hirai Y and Imaizumi T: Factors associated with serum high mobility group box 1 (HMGB1) levels in a general population. Metabolism 58(12): 1688-1693, 2009. PMID: 19616266. DOI: 10.1016/j.metabol.2009.05.024

25 Goldstein RS, Gallowitsch-Puerta M, Yang L, Rosas-Ballina M, Huston JM, Czura CJ, Lee DC, Ward MF, Bruchfeld AN, Wang H, Lesser ML, Church AL, Litroff AH, Sama AE and Tracey KJ: Elevated high-mobility group box 1 levels in patients with cerebral and myocardial ischemia. Shock 25(6): 571-574, 2006. PMID: 16721263. DOI: 10.1097/01.shk.0000209540.99176.72
Received May 17, 2021

Revised May 27, 2021

Accepted May 31, 2021 